\section{Detection of intravascular injection of regional anaesthetics in children}

Myron Yaster MD

Purpose: Detection of intravascular injection of local anaesthetic during placement of regional blocks in children by using epinephrine-induced tachycardia or hypertension may produce false positive and false negative findings. This study evaluates ECG changes as markers of intravascular injection of local anaesthetics with epinephrine. during placement of epidural blocks in children.

Methods: Observational study in a teaching hospital of all epidural anaesthetics administered to paediatric patients during one year. General anaesthesia. where used, was not controlled. An ECG ithythm strip was recorded during test dose injection and analyzed for changes in rate, thythm, and T-wave configuration.

Results: During the study period. 742 paediatric epidural blocks were administered. There were 644 caudal (284 without catheters), 97 lumbar, and one thoracic epidural anaesthetics. Satisfactory placement was achieved in $97.7 \%$ of patients. Intravascular injection was detected in $42(5.6 \%$ ) of epidural anaesthetics (3.8\% and $6.7 \%$ of straight needle and catheter injections, respectively). Detection was by immediate aspiration of blood in six patients, and by heart rate increases $>10 \mathrm{bpm}$ in 30 . Five had heart rate decreases suggesting a baroreceptor response. Five had heart rate increases $<10 \mathrm{bpm}$ that were possible responses to noxious stimuli. Of 30 patients with known intravascular injection and for whom ECG strips were available, 25 (83\%) had T-wave amplitude increases $>25 \%$, and $29(97 \%)$ had ECG changes in T-wave or rhythm in response to the epinephrine injection. There were no false positives.

Conclusion: In order to reduce risks associated with epidural anaesthesia in children, epinephrine should be added to the local anaesthetic test dose, the ECG should be monitored continuously for changes in heart rate, rhythm, and T-wave amplitude. Epidural injections should be given in small increments.

Objectif : La détection de linjection intravasculaire d'anesthésique local pendant l'administration d'un bloc régional chez l'enfant par la tachycardie et l'hypertension peut donner lieu à des faux positifs et des faux négatifs. Cette étude évalue les changements de l'ÉCG comme indices d'injection intravasculaire d'anesthésiques locaux adrénalinés pendant l'administration du bloc.

Méthodes : L'inventaire de toutes les anesthésies épidurales administrées à des enfants pendant une année dans un hôpital d'enseignement. L'anesthésie générale était un critère d'exclusion. Un bande de rythme ÉEG était enregistrée pendant l'injection de la dose test et examinée relativement aux changements de fréquence, de rythme et de configuration de londe $\mathrm{T}$.

Résultats : Pendant la période d'étude, 742 blocs épiduraux pédiatriques ont été administrés, dont 644 anesthésies caudales (284 sans cathéter). 97 lombaires et une épidurale thoracique avec succès dans $97.7 \%$ des patients. Une injection intravasculaire est survenue au cours de 42 (5.6\%) anesthésies épidurales (3.8\% par l'aiguille et $7.6 \%$ par le cathéter) et a été détectée par l'aspiration immédiate de sang chez six patients et par une augmentation de la fréquence cardiaque $>10 \mathrm{bpm}$ chez 30 . La fréquence a diminué chez cinq patients suggérant une réponse barotropique. Cinq ont présenté des augmentations de fréquence $<10 \mathrm{bpm}$ en réaction possible aux stimuli nocifs. Sur 30 patients chez qui l'injection intravasculaire était claire et chez qui des bandes de rythme étaient disponibles. 25 (83\%) présentaient une augmentation de l'amplitude de l'onde $T>25 \%$, et 29 (97\%) avaient des changements de l'onde $T$ ou du rythme en réponse à l'injection d'épinéphrine. II riy a pas eu de faux positifs.

Conclusion : Pour réduire les risques associés à l'anesthésie épidurale chez l'enfant, de l'épinéphrine devrait être ajoutée à la dose test d'anesthésique local et l'ÉCG devrait être monitoré en continu pour révéler les changements de fréquence, du rythme et d'amplitude de l'onde T. L'anesthésique local doit être administré dans l'espace épidural en petites doses répétées.

From the Department of Anaesthesiology and Critical Care Medicine, Johns Hopkins University, 600 Norch Wolfe Streer, Halsted 842, Baltimorc, MD 21287-5842; Phone: 410-955-2393; Fax: 410-614-2911. Address correspondence to: Dr. Quentin A. Fisher. Accepted for publication January 25, 1997. 


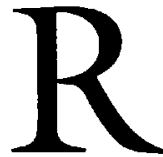

EGIONAL anaesthesia, particularly the epidural administration of bupivacaine or lidocaine, is frequently used as an adjunct to general anaesthesia for surgical procedures in infants and children. Most commonly, epidural anaesthesia is initiated in a child already under general anaesthesia. The most serious complications, convulsions and cardiovascular collapse, may occur if large doses of local anaesthetic are absorbed from the injection site, or when small doses are injected into a vein. Cardiac arrest may not be heralded by warning signs and resuscitation is generally difficult. ${ }^{1-6}$ As a result, a variety of strategies has evolved for reliably detecting intravascular injection while also avoiding the unnecessary discontinuation of an effective regional technique. ${ }^{7}$ In awake adults, changes in sensorium or segmental sensory level may be helpful, but in anaesthetized children, detection relies on aspiration of blood through the needle or catheter, or haemodynamic changes in response to epinephrine added to the local anaesthetic.

Epinephrine-induced tachycardia is the most commonly-sought signal of an inadvertent intravascular injection. However, the effect of small doses of epinephrine on the heart rate depends on the dose given, and the intensity of the accompanying baroreceptor response. ${ }^{8,9}$ Since the number of beats per minute change regarded as positive is somewhat arbitrary, the possibility of a false diagnosis exists, ${ }^{10-12}$ and could thus contribute to either a local anaesthetic toxic reaction or abandonment of a well-functioning regional technique. Several studies and case reports employing known direct intravenous injection of local anaesthetic with epinephrine have demonstrated substantial problems with both false negative (no heart rate change in the presence of intravascular injection) and false positive (change in heart rate when no intravascular injection took place) observations. ${ }^{1,10,11}$ False negative responses have been attributed to heart-rate slowing effects of halothane, baroreceptor reflexes, and an autonomic balance favouring parasympathetic tone in infants and children. Even previous treatment with atropine has not made test-dosing with epinephrine-containing solutions completely sensitive in detecting intravascular injections when based on heart rate changes. ${ }^{10,11} \mathrm{~A}$ false positive assessment may result because of cardiovascular responses to epidural needle placement, positioning the patient while lightly anaesthetised, or surgical stimulation.

A false positive assessment of intravascular injection may result from adrenergic responses to needle puncture or movement under anaesthesia. Although it has been suggested that isoproterenol may be a more reliable marker than epinephrine, ${ }^{13}$ it is not likely to be labeled for neuraxial injection.
In several patients, we have noticed transient changes in the electrocardiogram characterized by ST elevation and increased $\mathrm{T}$-wave amplitude following intravenous injection of epinephrine as a vasopressor or unintentional intravascular injections of bupivacaine with epinephrine in doses calculated to give $0.2-1.0 \mu \mathrm{g} \cdot \mathrm{kg}^{-1}$ of epinephrine. If these changes reliably occur regardless of heart rate or baroreceptor responses, they could serve as markers of intravascular injection during regional anaesthesia in children.

This study was undertaken to determine prospectively if ECG changes in ST segments and T-waves can be used as clinical signs indicating inadvertent intravascular injection of local anaesthetics with epinephrine in infants and children.

\section{Methods}

With approval of the institutional review board, all epidural anaesthetics administered by the Pediatric Anaesthesia Service for elective and emergency surgery, during the year beginning September 1, 1994 were prospectively evaluated. No attempt was made to control the anaesthetic technique. Epidural anaesthetics were placed either through a $20 \mathrm{~g}$ catheter threaded through a $17 \mathrm{~g}$ needle (Tuohy or Crawford), or given as a "single shot caudal" through a $22 \mathrm{~g}, 1^{1 / 2}$-inch straight needle. For every epidural anaesthetic placed, data were collected which included patient demographics, general anaesthetics or sedatives in use during epidural anaesthetic placement, and results of the test dose injection. The test dose was defined as the initial fraction of the total dose during which observation for adverse reactions are made. During the test dose injection, a printed ECG trace (lead I and/or II) was recorded from the operating room monitor for a minimum of $60 \mathrm{sec}$. Intravascular placement of the needle or catheter was determined by the attending anaesthesiologist if blood was aspirated, or there were clinically important changes in heart rate or blood pressure (BP) with injection of the anaesthetic-epinephrine mixture. Analysis of T-waves was not advocated to clinicians as a method of detecting intravascular injection.

If the epidural needle or catheter was repositioned or replaced, data were collected for subsequent injections, but the outcome was tabulated as a single epidural. The ECG tracings from all patients were examined for heart rate, T-wave changes, and arrhythmias. Amplitude of Twaves was measured from the isoelectric $\mathrm{P}-\mathrm{QRS}$ line to the peak of the T-wave. A T-wave change was considered significant if the amplitude increased by $>25 \%$ for $10 \mathrm{sec}$. compared with baseline. This was chosen as a change that could be easily recognized on an ECG monitor. Since anaesthetic techniques were not controlled, no attempt was made to statistically compare positive and negative responses. 


\section{Results}

There were 742 epidural anaesthetics administered to 709 patients ( 24 male patients had 57 operations during the year), 526 boys and 183 girls (Figure 1 and Table I). Of the 644 caudal epidural anaesthetics, 284 were administered as a single dose through a straight needle. The remaining epidural anaesthetics were administered through a catheter placed via a caudal route in 360, lumbar in 97 and thoracic in one instance. Bupivacaine $0.25 \%$ with epinephrine 1:200,000 was used for $735(98.9 \%)$ of the test doses; lidocaine 1-2\% with epinephrine 1:200,000 was used in the others. The dose of epinephrine given with the test dose ranged from 2 to $30 \mu \mathrm{g}$, but on a weight basis was greater in smaller children (Figure 2).

One major complication occurred during the study, retention of a broken caudal catheter tip upon removal in a 23-mo-old boy; it was later removed surgically. There were no episodes of convulsions or lifethreatening arrhythmias.

In 42 epidural anaesthetics (5.6\%), there was evidence of intravascular entry. Of these, 14 (1.8\%) were abandoned after unsuccessful attempts to reposition or replace them (Table I); three others (not associated with intravascular entry) were abandoned because of technical problems with the catheter. Thus, satisfactory placement was achieved in $725(97.7 \%)$ of all epidural anaesthetics. Twenty percent of all patients, and $28 \%$ of those with intravascular entry were less than one year of age (Figure 1).

Of the 42 epidural anaesthetics with intravascular entry, six were detected by aspiration of blood before injection; 30 were suspected because of heart rate

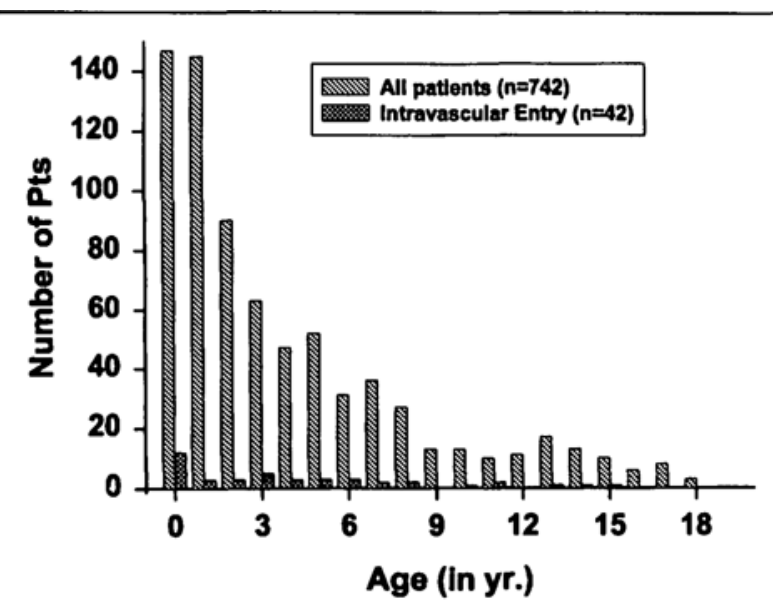

FIGURE I Age distribution of all patients and those with intravascular entry.

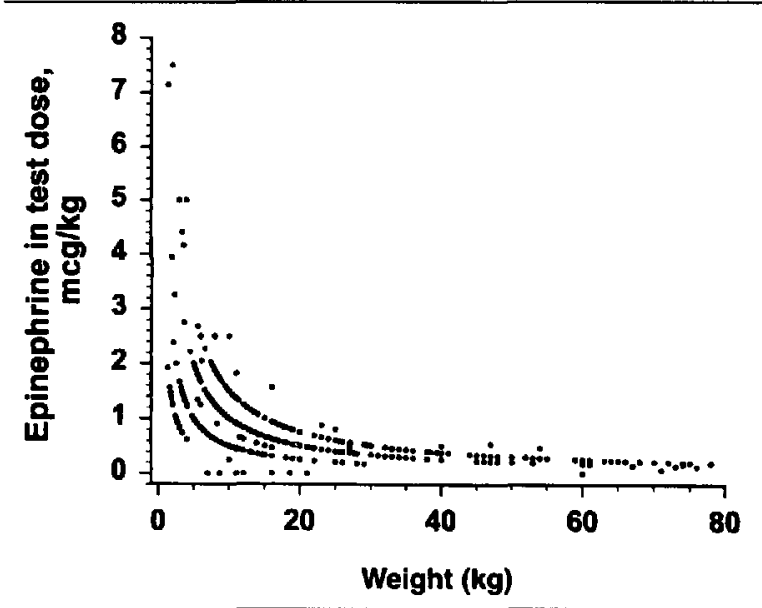

FIGURE 2 Epinephrine used in test dose, by body weight.

TABLE I Outcome of epidural anaesthetic placements

\begin{tabular}{|c|c|c|c|c|}
\hline Route and outcome & Total & $\begin{array}{l}\text { Satisfactory } \\
\text { first placement }\end{array}$ & replaced or repositioned & discontinued \\
\hline Single dose via straight needle & 284 & $272(95.8 \%)$ & $\begin{array}{l}6 \text { - Intravascular entry } \\
\text { 1- nonfunction }\end{array}$ & 5 - Intravascular entry \\
\hline Catheter & 458 & 415 (90.6\%) & $\begin{array}{l}22 \text { - Intravascular entry } \\
5 \text { - nonfunction } \\
4 \text { - ambiguous test dose } \\
\quad \text { interpretation }\end{array}$ & $\begin{array}{l}9 \text { - Intravascular entry } \\
2 \text { - nonfunction } \\
1 \text { - ambiguous test dose } \\
\text { interpretation }\end{array}$ \\
\hline Total & 742 & $687(92.6 \%)$ & $38(5.1 \%)$ & $16(2.3 \%)$ \\
\hline
\end{tabular}

TABLE II Detection of intravascular injections

\begin{tabular}{lccccc}
\hline & Total & $H R^{*} \uparrow$ & $H R \downarrow$ & $\begin{array}{c}\text { Blood aspirated } \\
\text { befort injection }\end{array}$ & $\begin{array}{c}\text { Blood aspirated } \\
\text { after injection }\end{array}$ \\
\hline $\begin{array}{l}\text { Single dose via } \\
\text { straight needle }\end{array}$ & 11 & 7 & 0.00 & 3 & 3 \\
Catheter & 31 & 23 & 5 & 3 & 9 \\
\hline
\end{tabular}

${ }^{*} H R=$ beart rate 


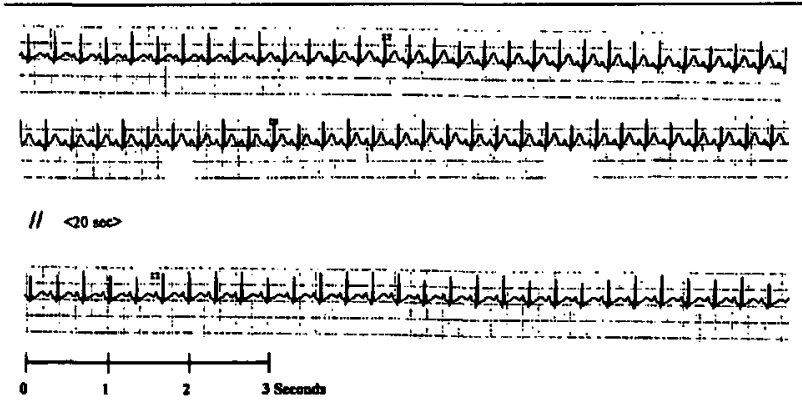

FIGURE 3A ECG traces exemplifying changes discussed in the text. $B G$, age $3 \mathrm{wk}(2 \mathrm{~kg})$. Increase in amplitude of T-wave in response to test dose of $0.5 \mathrm{ml}$ bupivacaine $0.25 \%$ with $2.5 \mu \mathrm{g}$ epinephrine. Note lack of change in heart rate, but unequivocal T-wave changes (upper trace), which returned to normal within $20 \mathrm{sec}$ (lower trace). Anaesthesia with thiopentone, halothane and pancuronium.

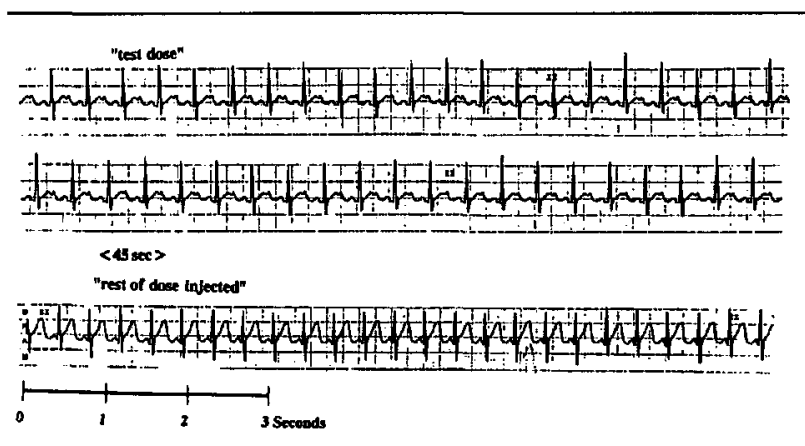

FIGURE 3B $\cdot \mathrm{CJ}$, age $16 \mathrm{mo} .(7.8 \mathrm{~kg})$. Possible false positive ECG. Negative test dose $1.0 \mathrm{ml}$ bupivacaine $0.25 \%$ with $5 \mu \mathrm{g}$ epinephrine (upper trace). Prominent T-wave changes were noted after injection of

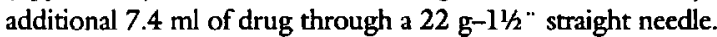

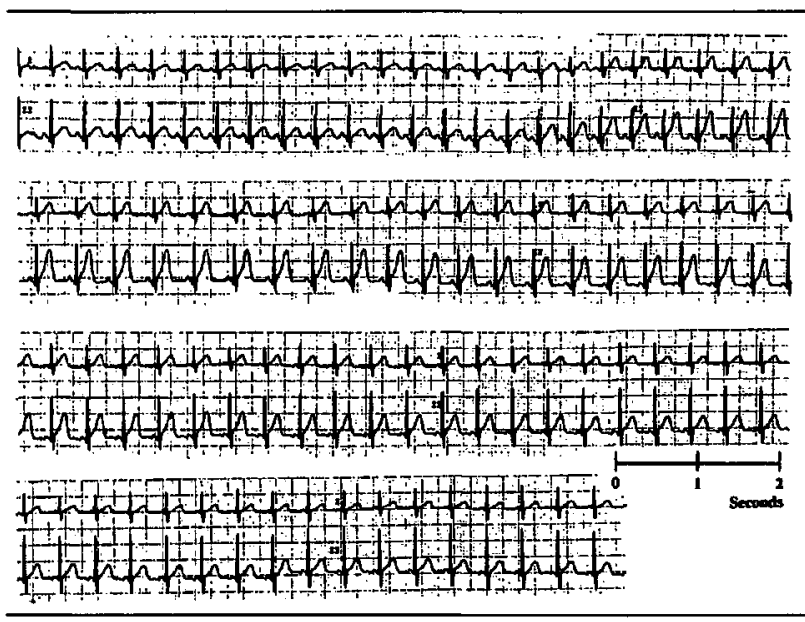

FIGURE 3C AC, age $8 \mathrm{mo}(8.5 \mathrm{~kg})$, continuous trace. Increased amplitude of $\mathrm{T}$-wave in response to test dose of $2.0 \mathrm{ml}$ bupivacaine $0.25 \%$ with $10 \mu \mathrm{g}$ epinephrine. Slight heart rate increase $148 \rightarrow 154$ bpm, followed by slowing to $137 \mathrm{bpm}$. Anaesthesia with halothane and pancuronium. increases $>10 \mathrm{bpm}$, and five were suspected because of heart rate decreases suggesting a baroreceptor response (one had previous treatment with atropine), and confirmed by additional test dosing or aspiration of blood (Table II). One patient (three weeks old; caudal catheter) had a heart rate change from 189 to $194 \mathrm{bpm}$, no change in systolic BP, but unequivocal changes in the $\mathrm{T}$-wave, leading to replacement of the catheter (Figure 3A). In 12 of the 42 patients, aspiration of blood occurred only after test dose injection.

Equivocal assessments of the test dose also occurred in five patients, all with caudal catheters. In four, heart rate increases were $<10 \mathrm{bpm}$. The fifth had biphasic $\mathrm{P}$-waves in sinus rhythm, with no change in heart rate. In these five patients with equivocal test doses, no BP increases occurred, and none had blood aspirated. In four, the catheter was repositioned and later used intraoperatively without difficulty. In one, the regional anaesthetic was abandoned.

Atropine was given during induction to $30 \%$ of all patients. Of those with intravascular injection, 37\% (11 of 30) of those with a heart rate increase had received atropine; $33 \%$ of those without a heart rate increase (two of six) had received atropine.

Of the 36 patients whose test dose resulted in a diagnosis of intravascular injection, ECG traces were available for analysis in 30 . In 25 , transient increase in T-wave amplitude ranged from 33 to $250 \%$ (mean $157 \%$ ) of baseline, and lasted 15-30 sec (Figure 3C). When present, $\mathrm{T}$-wave increases typically preceded heart rate or BP change. Other ECG changes (Table III) were also observed including abrupt change to nodal and ventricular brady arrhythmia in two patients (Figure 3D) and reduction of T-wave amplitude in sinus rhythm in 2 patients (Figure 3E). Thus, in 29 of 30 patients for whom ECG tracings were available, epinephrine-induced changes in the ECG provided evidence of intravascular injection.

For those patients in whom an intravascular injection did not occur (700 patients) ECG traces were available for $539(77 \%)$. Isolated T-wave amplitude increases of $33-50 \%$ could be found in $44(8.1 \%)$ of these negative tracings, due to baseline variability or patient repositioning. The changes were not sustained for more than four beats, nor did they demonstrate the characteristic crescendo-decrescendo pattern seen in confirmed intravascular injections. In one additional trace (Figure 3B) no changes occurred in response to the test dose, but a prominent, sustained increase in T-wave amplitude, accompanied by increased heart rate occurred with injection of the rest of the "single shot" dose. It is likely that this did, in fact represent 
an intravascular injection, but the anaesthetist's clinical impression was that it did not.

During the course of the study, ECG traces also became available in five children in whom epineph-

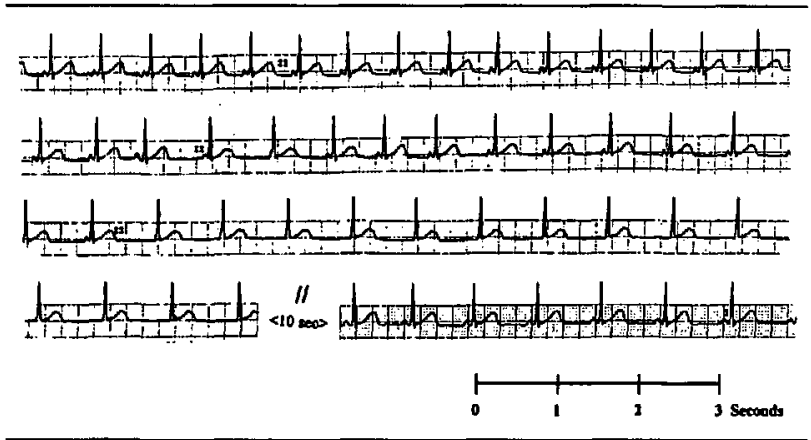

FIGURE 3D EB, age $2 \frac{1}{2}$ yr $(14 \mathrm{~kg})$. Heart rate slowing $(93 \rightarrow 85$ $\mathrm{bpm}$ ) with onset of nodal bradycardia in response to test dose of $2 \mathrm{ml}$ bupivacaine $0.25 \%$ with $10 \mu \mathrm{g}$ epinephrine. No T-wave change is noted. Anaesthesia with isoflurane and d-tubocurarine.

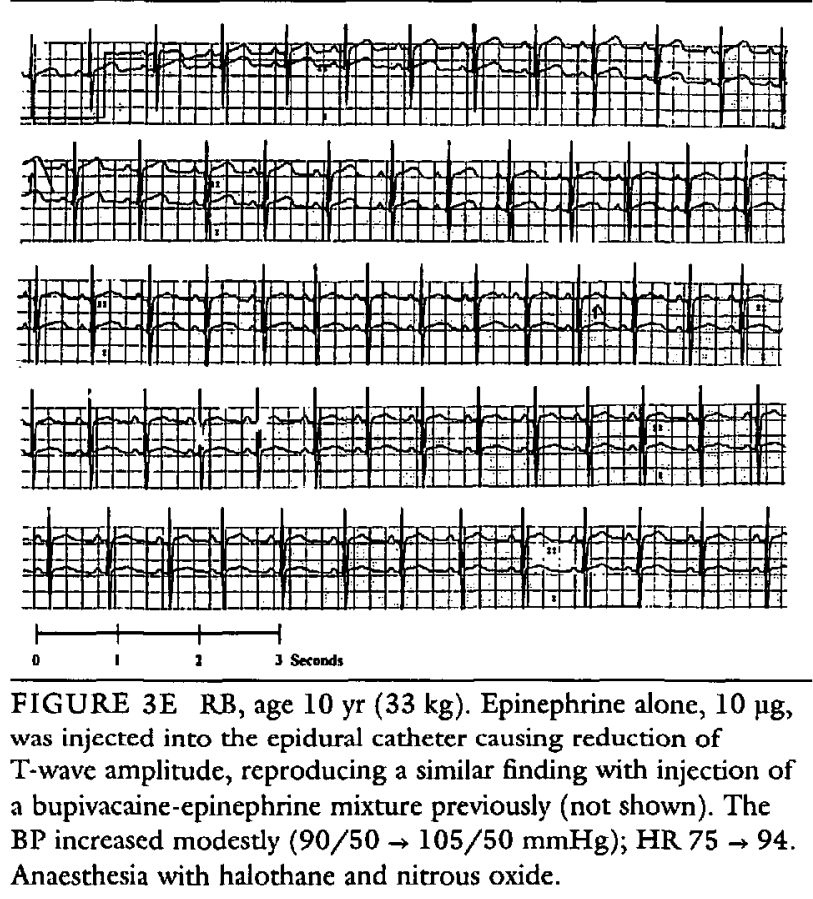

rine was given as a vasopressor intraoperatively. Four had prominent increases in $\mathrm{T}$-wave amplitude (Figure 3F), and one had a decreased amplitude (Figure 3G).

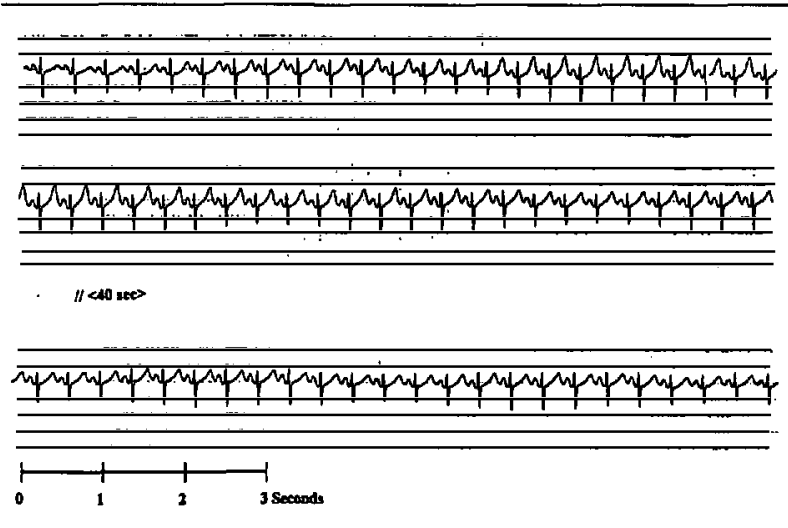

FIGURE 3F SB, age 6 yr $(28 \mathrm{~kg})$. Prominent T-wave change in response to $i v$ administration of epinephrine $10 \mu \mathrm{g}$ for hypotension during emergency open reduction of forearm fracture. Initial BP 45/33; HR $134 \mathrm{bpm}$. Following treatment: BP 82/46 $\mathrm{mmHg}, \mathrm{HR} 154 \mathrm{bpm}$. Anaesthesia with thiopentone, succinylcholine, isoflurane and nitrous oxide.

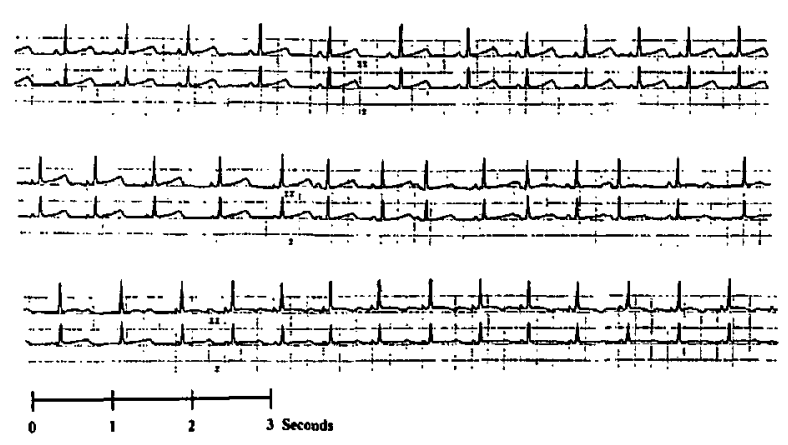

FIGURE 3G MR, age $6 \mathrm{yr}(25 \mathrm{~kg})$. Reduction of T-wave amplitude in response to iv administration of epinephrine $10 \mu \mathrm{g}$ for hypotension during laminectomy. Initial BP 69 mmHg systolic; HR $85 \mathrm{bpm}$. Following treatment BP $94 \mathrm{~mm}$ $\mathrm{Hg}$ systolic, HR $98 \mathrm{bpm}$. Anaesthesia with isoflurane, fentanyl, and pancuronium.

TABLE III Patients with intravascular injection but without increased T-wave amplitude

\begin{tabular}{lllll}
\hline Pt ID/age & Heart rate change, bpm & BP change $^{*}$ & T-wane response & Comment \\
\hline JS $/ 14$ yr & $78 \rightarrow 102$ & $\mathrm{NR}^{\dagger}$ & no change & Blood aspirated after injection \\
$\mathrm{AP} / 1.4 \mathrm{yr}$ & $135 \rightarrow 108$ & $80 \rightarrow 120$ sys & no change & change to nodal rhythm \\
$\mathrm{EB} / 2.5 \mathrm{yr}$ & $95 \rightarrow 76$ & $\mathrm{NR}$ & amplitude $\downarrow$ & change to nodal rhythm \\
$\mathrm{RB} / 10 \mathrm{yr}$ & $70 \rightarrow 89$ & $90 \rightarrow 105$ sys & amplitude $\downarrow$ (Figure 3E) & similar change when epinephrine only injected \\
$\mathrm{AM} / 6 \mathrm{yr}$ & $95 \rightarrow 81$ & $\mathrm{NR}$ & amplitude $\downarrow$ & Blood aspirated after injection \\
\hline
\end{tabular}

*Blood pressure, in $\mathrm{mmHg}$

${ }^{\dagger} N R=$ not recorded 


\section{Discussion}

Among the complications of regional anaesthesia, the most dreaded are the abrupt onset of seizures and lethal cardiac arrhythmias from intravascular injection. Although the detection of heart rate change from small doses of epinephrine given in a "test dose" has been commonly used as a means of detecting intravascular injection, its reliability has been questioned. ${ }^{10-12}$ In our study, we found heart rate change signaled intravascular injection in 30 of 36 in whom it could be confirmed, for a sensitivity of $\mathbf{8 3} \%$. Since it cannot be known exactly how much of the test dose enters the vascular space, it is uncertain whether this lack of sensitivity is due to the variable human response to epinephrine, or to inadequate dose for a $B$-receptor response. Even with direct intravenous injection, Desparmet ${ }^{10}$ found heart rate did not increase by $>10$ bpm in $39 \%$ of children not pre-treated with atropine, and $5 \%$ of those that were.

We have demonstrated that T-wave change in the ECG is another signal of intravenous epinephrine injection. The most prominent change is increased amplitude of the T-wave, lasting from 15 to $45 \mathrm{sec}$, which occurred in 25 of 30 patients in our study. Other ECG changes that were also observed in patients with a positive test dose included abrupt change to nodal brady arrhythmia and reduction of T-wave amplitude. Thus, in 29 of 30 patients for whom ECG traces were available, epinephrine-induced changes in the ECG provided evidence of intravascular injection.

False positive ECG changes were not observed in 539 negative test doses for which ECG traces were available. One patient whose test dose showed no ECG change did have characteristic T-wave and heart rate increases after injection of additional $7.4 \mathrm{ml}$ bupivacaine-epinephrine mixture. Whether this truly represents a false positive, or is the result of partial intravascular injection (perhaps through movement of the needle during injection) is unclear.

It is not known why the T-wave changes occur with epinephrine injection in children. This was first reported in paediatric epidural anaesthetic test-dosing in $1993,{ }^{14}$ and was thought to be due to the amide anaesthetic. However, giving children epinephrine alone as a vasopressor $\left(0.5-2.5 \mu \mathrm{g} \cdot \mathrm{kg}^{-1}\right)$ causes T-wave changes. In adults, flattening or inversion of the $\mathrm{T}$-wave has been observed in response to physical and mental stress and coping, ${ }^{15,16}$ intravenous infusions of epinephrine, ${ }^{17,18}$ and absorption from lidocaine-epinephrine brachial plexus blockade. ${ }^{19,20}$ Studies in experimental animals have found increased T-wave amplitude from iv bupivacaine ${ }^{21}$ and $i v$ epinephrine, with and without bupivacaine. ${ }^{22}$ The metabolic effects of epinephrine include reductions in serum concentrations of potassium, magnesium, calcium, and phosphate, all of which may have an impact on conductivity and repolarization. Additional factors to consider are possible age-specificity, bolus vs infusion, and concomitant administration of general anaesthesia.

Since the anaesthetic techniques and epidural doses were not controlled, observations from this study cannot determine the sensitivity or specificity of ECG changes to detect intravascular injection in children. We also did not determine if the injection of epinephrine in doses too small to cause noticeable hemodynamic effects regularly causes $\mathrm{T}$-wave changes. The thresholds for the other effects of epinephrine (such as changes in heart rate, glucose, alanine, or growth hormone) are variable, ranging from twice to ten times the basal levels. ${ }^{23}$ Our observations suggest that further controlled studies are warranted to examine the predictive value and dose-related threshold for T-wave changes.

Among our patients, simple detection of blood in the needle or catheter would have failed to detect $57 \%$ (24 of 42) of intravascular entries. Epinephrine-induced heart rate change $>10 \mathrm{bpm}$ would have failed to detect intravascular injection in $17 \%$ (6 of 36) patients, and would have resulted in the unnecessary discontinuation of regional anaesthesia in five of 742 . Use of the electrocardiogram would have detected four additional intravascular injections and, although it was not advocated during the study, was the sole means by which intravascular entry was discovered in one.

From these observations, we make the following recommendations regarding detection of intravascular injection of epidural anaesthetics in children: 1) Injections should be given in small increments, with frequent aspiration, since blood may not be drawn until after a test dose is injected. 2) Epinephrine should continue to be used as a marker for epidural test doses in children. 3) The ECG should be continuously monitored for $\mathrm{T}$-wave changes or arrhythmias during injection of anaesthetic-epinephrine combinations.

\section{Acknowledgments}

The authors would like to thank Lisa Carlson, Trudy Campbell, and Jules Jung for tabulation of data. The authors are also indebted to the anaesthesiologists and resident staff of Johns Hopkins University for collection of data and ECG traces.

\section{References}

1 Albright $G$. Cardiac arrest following regional anesthesia with etidocaine or bupivacaine. Anesthesiology 1979; 51: 285-7.

2 Maxwell LG, Martin LD, Yaster $M$. Bupivacaineinduced cardiac toxicity in neonates: successful treatment with intravenous phenytoin. Anesthesiology 1994; 80: 682-6. 
3 Matsumiya N, Dobi S, Takabashi $H$, Kondo $\Upsilon$, Naito $H$. Cardiovascular collapse in an infant after caudal anesthesia with a lidocaine-epinephrine solution. Anesth Analg 1986; 65: 1074-6.

4 Prentiss JE. Cardiac arrest following caudal anesthesia. Anesthesiology 1979; 50: 51-3.

$5 \mathrm{Lumb} A B$, Carli $F$. Respiratory arrest after a caudal intravenous injection of bupivacaine. Anaesthesia 1989; 44: 324-5.

6 Ved SA, Pinosky M, Nicodemus $H$. Ventricular tachycardia and brief cardiovascular collapse in two infants after caudal anesthesia using a bupivacaine-epinephrine solution. Anesthesiology 1993; 79: 1121-3.

7 Colonna-Romano P, Lingaraju N, Godfrey SD, Braitman LE. Epidural test dose and intravascular injection in obstetrics: sensitivity, specificity, and lowest effective dose. Anesth Analg 1992; 75: 372-6.

8 Guinard J-P, Mulroy MF, Carpenter RL, Knopes $K D$. Test doses: optimal epinephrine content with and without acute beta-adrenergic blockade. Anesthesiology 1990; 73: 386-92.

9 Cryer PE. Physiology and pathophysiology of the human sympathoadrenal neuroendocrine system. $N$ Engl J Med 1980; 303: 436-44.

10 Desparmet J, Mateo J, Ecoffey C, Mazoit X. Efficacy of an epidural test dose in children anesthetized with halothane. Anesthesiology 1990; 72: 249-51.

11 Narchi $P$, Mazoit J-X, Coben S, Samii K. Heart rate response to an i.v. test dose of adrenaline and lignocaine with and without atropine pretreatment. $\mathrm{Br}$ J Anaesth 1991; 66: 583-6.

12 Kabn RL, Quinn TJ. Blood pressure, not heart rate, as a marker of intravascular injection of epinephrine in an epidural test dose. Reg Anesth 1991; 16: 292-5.

13 Perillo $M$, Sethna NF, Berde CB. Intravenous isoproterenol as a marker for epidural test-dosing in children. Anesth Analg 1993; 76: 178-81.

14 Freid EB, Bailey AG, Valley RD. Electrocardiographic and hemodynamic changes associated with unintentional intravascular injection of bupivacaine with epinephrine in infants. Anesthesiology 1993; 79: 394-8.

15 Guazzi $M$, Fiorentini $C$, Polese A, Magrini F, Olipari $M T$. Stress-induced and sympathetically-mediated electrocardiographic and circulatory variations in the primary hyperkinetic heart syndrome. Cardiovasc Res 1975; 9: 342-54.

16 Hijzen $T H$, Slangen $\pi$. The electrocardiogram during emotional and physical stress. Int J Psychophysiol 1985; 2: 273-9.

17 Hansen O, Jobansson BW, Gullberg B. Metabolic, hemodynamic, and electrocardiographic responses to increased circulating adrenaline: effects of pretreatment with class 1 antiarrhythmics. Angiology 1991; 42: 990-1001.
18 Struthers $A D$, Reid $J L$. Adrenaline causes hypokalacmia in man by $B 2$ adrenoceptor stimulation. Clin Endocrinol 1984; 20: 409-14.

19 Hahn RG. Decrease in serum potassium concentration during epidural anaesthesia. Acta Anaesthesiol Scand 1987; 31: 680-3.

20 Kubota $\Upsilon$, Toyoda $\Upsilon$, Kubota $H$, Asada A. Epinephrine in local anesthetics does indeed produce hypokalemia and ECG changes (Letter). Anesthesiology 1993; 77: 867.

21 Heavner JE. Cardiac dysrhythmias induced by infusion of local anesthetics into the lateral ceberal ventricle of cats. Anesth Analg 1986; 65: 133-8.

22 Kulier $A H$, Woeblck $H J$, Hogan $Q H$, et al. Epinephrine dysrhythmogenicity is not enhanced by subtoxic bupivacaine in dogs. Anesth Analg 1996; 83: 62-7.

23 Clutter WE, Bier DM, Shab SD, Cryer PE. Epinephrine plasma metabolic clearance rates and physiologic thresholds for metabolic and hemodynamic actions in man. J Clin Invest 1980; 66: 94-101. 